\title{
Tangier disease
}

INSERM

\section{Source}

INSERM. (1999). Orphanet: an online rare disease and orphan drug data base. Tangier disease. ORPHA:31150

Tangier disease (TD) is a rare lipoprotein metabolism disorder characterized biochemically by an almost complete absence of plasma high-density lipoproteins (HDL), and clinically by liver, spleen, lymph node and tonsil enlarg ement along with peripheral neuropathy in children and adolescents, and, occasionally, cardiovascular disease in adults. 